\title{
Decreased Striatal Monoaminergic Terminals in Olivopontocerebellar Atrophy and Multiple System Atrophy Demonstrated with Positron Emission Tomography
}

\author{
Sid Gilman, MD, ${ }^{*}$ Kirk A. Frey, MD, PhD, ${ }^{*} \dagger$ Robert A. Koeppe, PhD, $\dagger$ Larry Junck, MD,* \\ Roderick Little, PhD, $\ddagger$ Thierry M. Vander Borght, MD, PhD, $\dagger$ Mary Lohman, BA,* \\ Susan Martorello, MS, ${ }^{*}$ Lihsueh C. Lee, PhD,$\dagger$ Douglas M. Jewett, PhD, $\dagger$ \\ and Michael R. Kilbourn, $\mathrm{PhD} \dagger$
}

\begin{abstract}
We used $\left[{ }^{11} \mathrm{C}\right]$ dihydrotetrabenazine, a new ligand for the type 2 vesicular monoamine transporter (VMAT2), with positron emission tomography to study striatal monoaminergic presynaptic terminals in 4 patients with multiple system atrophy, 8 with sporadic olivopontocerebellar atrophy, and 9 normal control subjects. Specific binding in the striatum was significantly reduced in the multiple system atrophy patients as compared with the normal control group, with average reductions of $61 \%$ in the caudate nucleus $(p=0.002)$ and $58 \%$ in the putamen $(p=0.009)$. Smaller reductions were found in the sporadic olivopontocerebellar atrophy group, averaging $26 \%$ in the caudate nucleus $(p=0.05)$ and $24 \%$ in the putamen $(p=0.11)$. Mean blood-to-brain [ $\left.{ }^{11} \mathrm{C}\right]$ dihydrotetrabenazine transport $\left(\mathrm{K}_{1}\right)$ was significantly different between groups only in the cerebellum, with values for the sporadic olivopontocerebellar atrophy group diminished compared with the normal control group. Cerebellar $K_{I}$ was not significantly decreased in the multiple system atrophy group. The finding of reduced striatal VMAT2 in sporadic olivopontocerebellar atrophy patients suggests nigrostriatal pathology, indicating that some may later develop symptomatic extrapyramidal disease.
\end{abstract}

Gilman, S, Frey KA, Koeppe RA, Junck L, Little R, Vander Borght TM, Lohman M, Martorello S, Lee LC, Jewett DM, Kilbourn MR. Decreased striatal monoaminergic terminals in olivopontocerebellar atrophy and mulriple system atrophy demonstrated with positron emission tomography. Ann Neurol 1996;40:885-892

Multiple system atrophy (MSA) is a progressive neurological disorder consisting of combinations of extrapyramidal, pyramidal, cerebellar, and autonomic symptoms and signs [1-7]. The term "possible MSA" is used for patients with only extrapyramidal symptoms that are poorly responsive or unresponsive to levodopa (striatonigral degeneration [SND]) and patients with a combination of cerebellar ataxia and extrapyramidal symptoms [2]. The term "probable MSA" pertains to patients with extrapyramidal symptoms poorly responsive or unresponsive to levodopa accompanied by autonomic symptoms with or without pyramidal and cerebellar symptoms (Shy-Drager syndrome [SDS]) [2]. Similarly, the term "probable MSA" is applied to patients with cerebellar and autonomic symptoms with or without extrapyramidal and pyramidal symptoms [2]. The diagnosis of "definite MSA" requires a typical history and physical findings with subsequent postmortem verification [2]. In most patients with definite MSA, neuropathological examination demonstrates degenerative changes in the cerebellum and brainstem as well as the basal ganglia and spinal cord [8]. The neuropathological changes in MSA include those seen with SND [9-12], SDS [3, 13-16], and olivopontocerebellar atrophy (OPCA) [3, 6-8]. Neuronal loss and gliosis occur in the basal ganglia (putamen and globus pallidus), brainstem and cerebellum (substantial nigra, locus ceruleus, dorsal vagal nuclei, vestibular nuclei, inferior olives, pontine nuclei, and cerebellar Purkinje cells), and spinal cord (pyramidal tracts, intermediolateral columns, and Onuf's nuclei) $[1,7,8)$. Recently, oligodendroglial $[17-21]$ and neuronal [22-24] intracytoplasmic and intranuclear inclusions were observed with MSA.

OPCA is a neurodegenerative disorder occurring
From the *Department of Neurology; $\nmid$ Division of Nuclear Medicine, Department of Internal Medicine; and $\neq$ Department of Biostatistics, University of Michigan, Ann Arbor, MI.

Received Feb 1, 1996, and in revised form May 30. Accepted for publication May 31, 1996.
Address correspondence to Dr Gilman, Department of Neurology, University of Michigan Medical Center, 1550 E. Medical Center Drive, Ann Arbor, MI 48109-0316. 
both sporadically (sOPCA) and with dominant (dOPCA) and recessive (rOPCA) forms of hereditary transmission and characterized by progressive ataxia of gait and speech, disturbances of extraocular movements, and difficulty with limb coordination [25-29]. The neuropathological changes include loss of inferior olivary neurons and their climbing fiber projections to the cerebellum, decreased numbers of pontine neurons and their mossy fiber connections in the cerebellum, and marked reduction of Purkinje cells and granule cells $[7,30-32]$. Some patients initially diagnosed with sOPCA develop additional clinical signs characteristic of MSA, and at postmortem show degenerative changes not only within the brainstem and cerebellum, but also within the basal ganglia and spinal cord [1-4]. Most patients who present initially with OPCA and later develop clinical manifestations of MSA have the sporadic and not the hereditary form of the disorder [2]. The percentage of patients with sOPCA who later develop MSA is unknown, and no method is currently available to determine whether individual sOPCA patients will progress to develop MSA. Decreased striatal function that is not accompanied by clinical evidence of extrapyramidal disease might be expected in sOPCA patients who will develop MSA with time. A means of detecting striatal abnormalities in sOPCA patients would serve a useful function in permitting the distinction of "pure" OPCA and MSA earlier in their courses and thus in assisting with the prognosis of the disorder. The present investigation was designed to determine whether positron emission tomography (PET) might be used to detect abnormalities in striatal monoaminergic presynaptic terminals in parients with sOPCA.

Several radiopharmaceuticals have been utilized previously with PET to examine monoaminergic presynaptic terminals, but medication use and compensatory effects of disease processes affect the results. Recently our center developed $\left[{ }^{11} \mathrm{C}\right]$ dihydrotetrabenazine (DTBZ) to examine the density of binding to the type 2 vesicular monoamine transporter (VMAT2). Studies in animals suggested that this agent avoids the problems from disease-related compensation or medications encountered with previously used agents [33-35]. In the present study and a companion investigation [35], this new ligand was utilized to determine whether the density of monoaminergic terminals in the striatum is decreased with normal aging and in Parkinson's disease, in MSA, and in at least some patients with sOPCA. A preliminary version of the present study has been published [36].

\section{Materials and Methods}

\section{Patient Groups and Normal Subjects}

The Institutional Review Board approved the studies, and we obrained informed consent from each subject. Three groups were studied: 4 patients with probable MSA (age 71 \pm 9 years, mean \pm standard deviation), 8 patients with sOPCA (age $55 \pm 9$ years), and 9 normal control subjects (age $58 \pm 10$ years). The normal control subjects were selected on the basis of age from a larger group reported in the accompanying investigation, and included all subjects in the middle-age and elderly groups [35]. The control subjects had no history of neurological disorders and no abnormalities on general physical and neurological examinations. None of the patients or control subjects were receiving centrally active medications that influence studies of striatal VMAT2 binding (Table 1).

We studied 4 patients with probable MSA (see Table 1). The diagnosis of MSA was based on the demonstration of an extrapyramidal disorder with autonomic failure unresponsive or poorly responsive to levodopa (Patients 1 and 4, see Table 1) or a levodopa-unresponsive extrapyramidal disorder with autonomic failure and cerebellar dysfunction (Patients 2 and 3, see Table 1). The signs of disorders of extrapyramidal, cerebellar, and autonomic function were graded clinically as mild, moderate, or severe (see Table 1). We defined an extrapyramidal movement disorder as the presence of at least two of the following: akinesia, rigidity, tremor, and hypokinetic speech. We defined cerebellar dysfunction as the presence of at least two signs, limb or gait ataxia along with ocular dysmetria and ataxic dysarthria. We defined autonomic failure by the presence of postural hypotension, sexual impotence (in males), or urinary incontinence without outflow obstruction or disorders of bladder suspension. The criteria for postural hypotension included an orthostatic drop of $30 \mathrm{~mm}$ $\mathrm{Hg}$ or more in systolic blood pressure and $20 \mathrm{~mm} \mathrm{Hg}$ or more in diastolic blood pressure with an increase in heart rate of no more than 10 beats $/ \mathrm{min}$ [37]. Blood pressure and pulse were measured with the patient supine and again 2 minutes after the patient assumed a standing position. None of the patients were taking medications that induce postural hypotension.

Eight patients with sOPCA were studied. The diagnosis of SOPCA was based on a history of sporadically occurring progressive deterioration of cerebellar function manifested by at least two signs, limb or gait ataxia along with ocular dysmetria and ataxia dysarthria, in the absence of other disorders such as sensory loss adequate to cause ataxia, medications, toxins, evidence of a neoplasm in the cerebellum or elsewhere, or evidence of multiple sclerosis or other diseases that can cause progressive cerebellar ataxia. A careful family history was taken to ensure that the disorder was sporadic. The diagnosis was assisted by finding cerebellar and brainstem atrophy in magnetic resonance images (MRIs) in all of the patients studied (see Table 1), but this was not essential because OPCA can occur without demonstrable atrophy in anatomical imaging studies [38]. Three women with SOPCA (Patients 9, 10, and 12) had mild degrees of urinary incontinence, but this was attributed to peripheral bladder mechanics and not to autonomic involvement.

The patients were evaluated with a complete history, physical examination, neurological examination, laboratory tests to exclude other diseases, and MRI to exclude demyelinative disease and structural abnormalities. Speech was evaluated as described previously [39]. Laboratory tests included a com- 
Table 1. Clinical Features of the Patients with Multiple System Atrophy (MSA) and Sporadic Olivopontocerebellar Atrophy (sOPCA) ${ }^{\mathrm{a}}$

\begin{tabular}{|c|c|c|c|c|c|c|c|c|c|c|c|c|}
\hline & \multicolumn{12}{|c|}{ Patient No. } \\
\hline & 1 & 2 & 3 & 4 & 5 & 6 & 7 & 8 & 9 & 10 & 11 & 12 \\
\hline Sex & $\mathrm{F}$ & M & $M$ & M & $\mathrm{M}$ & $\mathrm{F}$ & $\mathrm{F}$ & $\mathrm{F}$ & $\mathrm{F}$ & $\mathrm{F}$ & M & $\mathrm{F}$ \\
\hline Age $(y r)$ & 69 & 67 & 64 & 84 & 46 & 63 & 46 & 44 & 62 & 61 & 57 & 61 \\
\hline Diagnosis & MSA & MSA & MSA & MSA & sOPCA & $s O P C A$ & sOPCA & sOPCA & sOPCA & sOPCA & sOPCA & sOPCA \\
\hline Medications ${ }^{b}$ & $\begin{array}{l}\text { Fluoxetine, } \\
20 \mathrm{mg} \\
\text { amitriptyline, } \\
50 \mathrm{mg}\end{array}$ & $\begin{array}{l}\text { Amitriptyline, } \\
30 \mathrm{mg} ; \\
\text { baclofen, } \\
30 \mathrm{mg}\end{array}$ & None & $\begin{array}{l}\text { Carbidopa/ } \\
\text { levodopa, } \\
125 / 500 \\
\text { Selegiline, } \\
5 \mathrm{mg}\end{array}$ & None & None & None & None & None & None & None & $\begin{array}{c}\text { Clonazepam, } \\
0.5 \mathrm{mg}\end{array}$ \\
\hline $\begin{array}{c}\text { Duration of symp- } \\
\text { toms (yr) }\end{array}$ & 4 & 10 & 3 & 6 & 3 & 6 & 2 & 7 & 5 & 2.5 & 1.5 & 3.5 \\
\hline Akinesia & +++ & ++ & + & + & - & - & - & - & - & - & - & - \\
\hline Rigidiry & $t+t$ & + & +++ & + & - & - & - & - & - & - & - & - \\
\hline Tremor ac rest & - & - & - & + & - & - & - & - & - & - & - & - \\
\hline Hypokinetic speech & $++t$ & $+t$ & + & $+t$ & - & - & - & - & - & + & - & - \\
\hline Ocular dysmetria & + & + & + & + & + & + & + & + & + & + & + & $+t$ \\
\hline Gait ataxia & - & + & +++ & - & ++ & + & + & ++ & + & + & $+t+$ & + \\
\hline Limb ataxia & - & + & + & - & + & + & + & + & + & + & + & + \\
\hline Ataxic speech & + & + & + & - & + & ++ & ++ & ++ & ++ & ++ & + & + \\
\hline Spastic speech & $+t$ & ++ & + & + & + & - & + & + & + & - & + & + \\
\hline $\begin{array}{l}\text { Extensor plantar } \\
\text { signs }\end{array}$ & + & - & - & - & - & - & - & - & - & - & - & - \\
\hline $\begin{array}{l}\text { Postural hypoten- } \\
\text { sion }\end{array}$ & +++ & + & +++ & +++ & - & - & - & - & - & - & - & + \\
\hline $\begin{array}{l}\text { Urinary inconti- } \\
\text { nence }\end{array}$ & ++ & - & - & + & - & - & - & - & + & + & - & + \\
\hline \multicolumn{13}{|l|}{ MRI findings } \\
\hline Striatum & - & - & - & - & - & - & - & - & - & - & - & - \\
\hline Cerebellar vermis & + & ++ & $\rightarrow$ & + & + & ++ & +++ & +++ & ++ & ++ & + & +++ \\
\hline $\begin{array}{l}\text { Cerebellar hem- } \\
\text { isphere }\end{array}$ & + & + & - & + & + & + & +++ & $t+t$ & $t+$ & ++ & + & $+t+$ \\
\hline Brainstem & + & + & - & + & + & + & ++ & +++ & + & ++ & + & +++ \\
\hline
\end{tabular}

${ }^{2}$ Rating scalc: $-=$ notmal; $+=$ mild; $++=$ moderate; $+++=$ severe. Trace levels were rated as normal.

"Doses are total received per day.

plete blood cell count; serum profiles of hepatic and renal function; brainstem auditory, visual, and somatosensory evoked potentials; serum levels of vitamins $E$ and $B_{12}$ and folic acid, and studies of thyroid funcrion. In patients with symptoms for less than 3 years, a search was made for an occult malignancy, including breast and pelvic examinations in women, prostate examination in men, acid phosphatase and prostate-specific antigen measurements, stool guaiac tests for occult blood, and chest $\mathrm{x}$-ray studies. In addition, antiPurkinje cell antibodies were sought in blood samples from patients with ataxia of less than 3 years' duration. All patients were evaluated with MRI to determine the extent of volume loss of the structures under study. The extent of volume loss was evaluated from the scans and is listed in Table 1. The neurological examinations were conducted by a neurologist (S.G.) blinded to the PET data.

\section{Positron Emission Tomography Studies}

DTBZ in racemic form was synthesized by $\left[{ }^{11} \mathrm{C}\right]$ methylation of 9-O-desmethyldihydrotetrabenazine. We administered by intravenous bolus $18 \pm 1 \mathrm{mCi}$ containing less than $50 \mu \mathrm{g}$ of mass of DTBZ and collected arterial blood samples and a sequence of 15 scans over the following 60 minutes [35].
PET studies were conducted similarly for all subjects. A catheter was placed in a radial artery for blood sampling. Radioactive fiducial markers placed on the scalp were used to register the dynamic sequence of frames, correcting for any motion that occurred throughout the study. The subjects lay quietly on a table, with cyes open and ears unoccluded and alert but not speaking. The subjects were imaged with a Siemens ECAT EXACT-47 PET scanner, which has an intrinsic in-plane resolution of $6.0-\mathrm{mm}$ full width at half maximum (FWHM) at the center of the field of view and an axial resolution of $5.0-\mathrm{mm}$ FWHM. The reconstructed resolution is approximately 9.0-mm FWHM. Forty-seven planes with a 3.375-mm center-to-center separation were imaged simultaneously. Attenuation correction was calculated by the standard ellipse method.

Anatomically configured volumes of interest (VOIs) were identified in summed activity maps from 0 to 7.5 minutes after injection. VOIs were placed in identical areas on all frames of the realigned dynamic sequence of scans for the caudate nucleus, putamen, thalamus, cerebellar hemispheres, and frontal correx. VOIs were acquired from three adjacent axial levels that best represented these structures. Data from the frontal cortex were used to normalize the dara taken from 
other regions in order to reduce variability in the quantitative measures.

\section{Pharmacokinetic Analysis}

The VOI data were fitted to a three-compartment tracer kinetic model using standard nonlinear least-squares parameter estimation. Kinetic rate constants $K_{1}$ to $k_{4}$ and cerebral blood volume were fitted parameters. Analysis resulted in regional estimates of ligand transport from plasma to brain $\left(\mathrm{K}_{1}\right)$, which is highly correlated with flow since the single-pass extraction fraction is approximately $50 \%$, and toral tissue distribution volume (DV) of DTBZ relative to plasma (DV $\left.=\left(\mathrm{K}_{1} / \mathrm{k}_{2}^{\prime}\right)\left(1+\mathrm{k}_{3}^{\prime} / \mathrm{k}_{4}\right)\right)[40]$.

\section{Data Analysis}

Determinations of DTBZ $\mathrm{K}_{1}$ and DV in individual structures were normalized to values from the frontal cortex, which contains very little VMAT2 and is relatively spared in the diseases under study. The regional total DV data were converted to specific DV by computing the following: (Regional DV - Frontal DV)/Frontal DV. Differences in specific binding between groups were tested with analysis of covariance (ANCOVA) adjusting for age, as explained below. A separate single-factor ANCOVA was tested for each of the four regions. For regions demonstrating a significant overall group difference, specific comparisons with two group $t$ tests were performed between groups. Significance levels for individual comparisons were not corrected for multiple comparisons, and no corrections were made for the effects of tissue atrophy.

\section{Age Effects}

In a concurrent investigation utilizing racemic DTBZ, we found a significant decline of striatal DV values with increasing age in a sampling of normal control subjects with a broader age range [35]. Accordingly, we utilized ANCOVA to adjust for age in our analysis, even though, in the subset studied, more limited ranges in age were included, and age was not significantly associated with the values of $K_{1}$ or specific binding in regions in which they distinguished the groups ( $p>0.05$ in all cases). The adjustment for age had only minor effects on the results.

\section{Results}

\section{$\left[{ }^{I}\right.$ C]Dibydrotetrabenazine Specific Binding}

ANCOVA revealed significant differences between groups in the caudate nucleus $\left(\mathrm{F}_{2,17}=7.2, p=0.005\right)$ and putamen $\left(\mathrm{F}_{2,17}=4.9, p=0.02\right)$ but not in the thalamus or cerebellum $(p>0.20)$. Adjusted means in the caudate nucleus and putamen were ordered as follows: MSA < sOPCA < control (Table 2, Figs 1, 2). Specifically, in the MSA group, the adjusted mean values for the caudate nucleus and putamen were significantly decreased in comparison to those for both normal control subjects and sOPCA patients. The magnitude of the decreases in specific binding below normal values in the MSA subjects averaged $61 \%$ in the caudate nucleus $(p=0.002)$ and $58 \%$ in the putamen $(p=0.009)$. Individual specific binding values
Table 2. [" ${ }^{11}$ CJDibydrotetrabenazine Specific Binding ${ }^{1}$

\begin{tabular}{lllll}
\hline & $\begin{array}{l}\text { Caudate } \\
\text { Gucleus }\end{array}$ & Putamen & Thalamus & Cerebellum \\
\hline $\begin{array}{c}\text { Control } \\
(n=9)\end{array}$ & $0.79 \pm 0.16$ & $0.78 \pm 0.22$ & $0.06 \pm 0.05$ & $-0.04 \pm 0.12$ \\
$\begin{array}{c}\text { sOPCA } \\
(n=8)\end{array}$ & $0.58 \pm 0.23^{\mathrm{h}}$ & $0.60 \pm 0.23$ & $0.03 \pm 0.06$ & $-0.09 \pm 0.09$ \\
$\begin{array}{c}\text { MSA } \\
(n=4)\end{array}$ & $0.30 \pm 0.16^{\mathrm{c}}$ & $0.33 \pm 0.21^{\mathrm{d}}$ & $0.05 \pm 0.16$ & $-0.17 \pm 0.17$ \\
\hline
\end{tabular}

"Values represent the mean \pm standard deviation. Means are age adjusted by analysis of covariance.

Significantly different from normal control value, $p=0.05$.

Significantly different from normal control value, $p=0.002$.

"Significantly different from normal control value, $p=0.009$

$s O l^{\prime} \mathrm{CA}=$ sporadic olivopontocerebellar atrophy; $\mathrm{MSA}=$ nultiple system atrophy.

in the caudate nucleus were reduced by more than 3 standard deviations below the normal control mean in 3 of the 4 MSA subjects. Specific binding in the putamen was reduced by more than 2.5 standard deviations in each of the same 3 patients. The fourth MSA patient, corresponding to the uppermost point in each of the four regions plotted in Figure 2, had relatively low specific binding values in the frontal cortex, and thus the data for this patient appear less decreased after normalization than before. For this patient, normalization of the values in the caudate nucleus and putamen to a different brain region such as the thalamus resulted in striatal decreases that were nearly equivalent to those of the other $3 \mathrm{MSA}$ patients. Independent evaluation of the MRIs of all 4 MSA patients by two of us (S. G., K. A. F.) blinded to the PET data revealed no greater evidence of frontal cortical atrophy in this patient than the other 3 . Thus, the findings in this patient do not appear to result from the effects of partial volume averaging owing to tissue atrophy.

In the sOPCA group the mean decrease of specific binding in comparison to the normal control values was not as great as in MSA, averaging $26 \%$ for the caudate nucleus $(p=0.05)$ and $24 \%$ for the putamen $(p=0.11)$ (see Table 2). Individual striatal specific binding values in SOPCA patients were more variable than those in MSA, with values for only 2 of 8 patients falling lower than 2 standard deviations below the control group mean for the caudate nucleus, and values for only 1 of 8 for the putamen.

\section{${ }^{I I}$ ClDihydrotetrabenazine Transport $\left(K_{l}\right)$}

Analysis of variance revealed significant differences between groups only in the cerebellum $\left(\mathrm{F}_{2,17}=6.4, p=\right.$ 0.008 ), where the means were in the following order: sOPCA $<$ MSA $<$ control. Subsequent pair-wise testing revealed that the only significant difference in cerebellar $\mathrm{K}_{1}$ between groups was a decrease in the sOPCA group as compared with the normal control group ( $\mathrm{Ta}$ ble 3). Although the MSA group showed no significant 


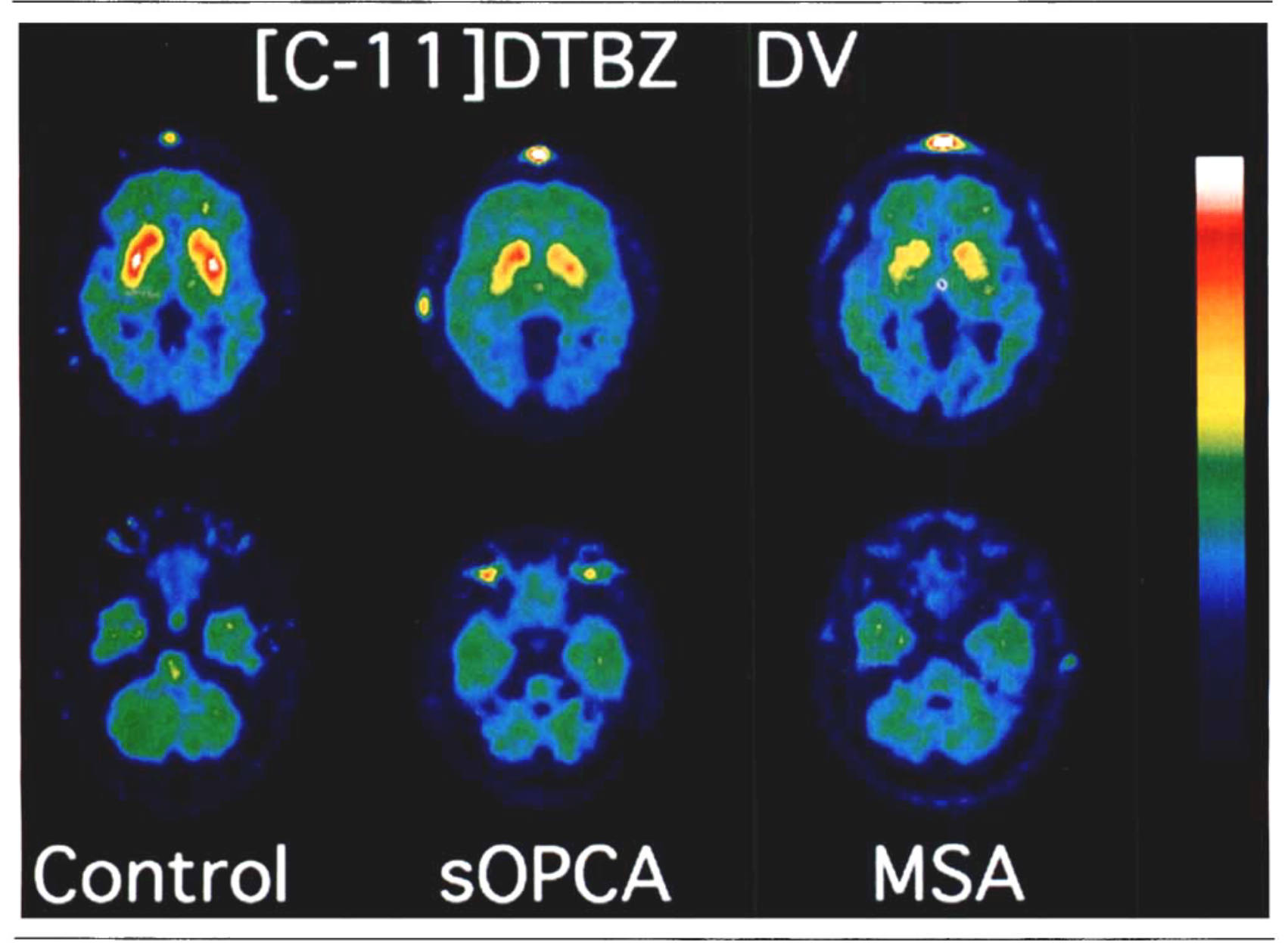

Fig 1. Distribution volume of $\left[{ }^{11}\right.$ C]dihydrotetrabenazine ([C-11]DTBZ DV) in the basal ganglia (upper row) and cerebellum (lower row) of a 69-year-old male normal control subject, compared to a 60-year-old woman with sporadic olivopontocerebellar atrophy (sOPCA) and a 63-year-old man with multiple system atrophy (MSA).

differences from control values, cerebellar $\mathrm{K}_{1}$ values for 2 of the 4 MSA patients were decreased to levels as low as the SOPCA values, but values for the other 2 were within the range of the normal control values. The 2 MSA patients with low cerebellar $K_{1}$ values had clinical signs of cerebellar dysfunction in addition to extrapyramidal and autonomic disturbances, whereas the other 2 patients had only extrapyramidal and autonomic signs.

\section{Discussion}

Many previous studies showed evidence of both striatal degeneration and decreased density of striatal monoaminergic presynaptic terminals in MSA. Investigations utilizing $\left[{ }^{18} \mathrm{~F}\right]$ fluorodeoxyglucose (FDG) to examine local cerebral metabolic rates for glucose revealed hypometabolism in the striatum [41--44] and also in the cerebral cortex $[42,44,45]$, cerebellum [44-46], thalamus [44], and brainstem [44]. PET studies with $\left[{ }^{18} \mathrm{~F}\right]$ fluorodopa in MSA patients revealed diminished striatal uptake, suggesting that nigrostriatal dopaminergic terminals are damaged [47-49].

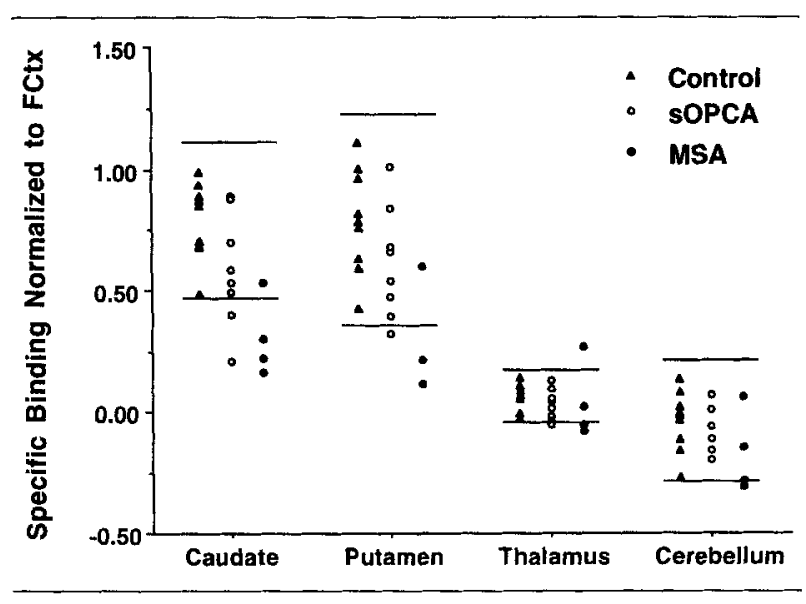

Fig 2. Specific binding of $\left[{ }^{11} C\right]$ dibydrotetrabenazine normalized to the frontal cortex (FCtx) in the caudate nucleus, putamen, thalamus, and cerebellum of individual normal control subjects (filled triangles) compared to patients with sporadic olivopontocerebellar atrophy (sOPCA, open circles) and patients with multiple system atrophy (MSA, filled circles). The horizontal bars indicate \pm 2 standard deviations about the normal control group mean. 
Table 3. ${ }^{I I}$ CJDihydrotetrabenazine Plasma-to-Brain

Transport $\left(K_{1}\right)$ Normalized to Frontal Cortex ${ }^{2}$

\begin{tabular}{|c|c|c|c|c|}
\hline Group & $\begin{array}{l}\text { Caudate } \\
\text { Nucleus }\end{array}$ & Putamen & Thalamus & Cerebellum \\
\hline Control & $1.00 \pm 0.12$ & $1.08 \pm 0.13$ & $1.25 \pm 0.07$ & $1.00 \pm 0.13$ \\
\hline sOPCA & $1.02 \pm 0.09$ & $1.11 \pm 0.05$ & $1.25 \pm 0.13$ & $0.73 \pm 0.15^{b}$ \\
\hline MSA & $1.02 \pm 0.14$ & $1.09 \pm 0.15$ & $1.22 \pm 0.09$ & $0.91 \pm 0.20$ \\
\hline
\end{tabular}

"Values represent the mean \pm standard deviation in the patients identified in Table 1. Means are age adjusted by analysis of covariance.

bignificantly different from normal control value, $p=0.002$.

sOPCA = sporadic olivopontocerebellar atrophy; $\mathrm{MSA}=$ multiple system atrophy,

Some evidence suggests that, similar to MSA patients, certain sOPCA patients have striatal degeneration, even though clinical signs of striatal injury are not evident in SOPCA. In a study with FDG and PET, MSA and SOPCA patients showed similar levels of hypometabolism in the striatum as well as the cerebral cortex, thalamus, brainstem, and cerebellum [44]. A PET study with $\left[{ }^{18} \mathrm{~F}\right]$ fluorodopa of patients with the predominantly cerebellar form of probable MSA revealed decreased striatal uptake of $\left[{ }^{18} \mathrm{~F}\right]$ fluorodopa even though striatal dysfunction was not the principal clinical manifestation [49]. The patients described in that report most likely had a disorder similar to the sOPCA patients in the present study. Our investigation was undertaken to utilize PET with a newly developed ligand, DTBZ, to determine whether the density of dopaminergic presynaptic terminals in the striatum is decreased in MSA and sOPCA. The form of DTBZ used in the present study is a racemic mixture, which has the disadvantage of a relatively high level of nonspecific binding. Our center has been successful in separating the enantiomers of DTBZ and has verified that the $(+)$ form is responsible for the specific activity. Currently this form is in use, and the ratio of specific to nonspecific activity is approximately twice the level of the racemic mixture of DTBZ. Although DTBZ does not differentiate between dopaminergic, noradrenergic, or serotonergic terminals, the concentration of dopaminergic terminals in the striatum is very much higher than that of noradrenergic or serotonergic terminals; thus, the ligand serves as an excellent marker of the density of striatal dopaminergic endings [50].

Studies in animals suggested that DTBZ permits examination of the density of the VMAT2 binding site without effects from medication and the compensatory effects of disease processes, which can influence the results of studies with $\left[{ }^{18} \mathrm{~F}\right]$ fluorodopa, WIN, and carbomethoxy-3- $\beta$-(4-lodophenyl)tropane ( $\beta \mathrm{CIT}$ ) [33-35]. Although the findings in animals have not been confirmed in human studies as yet, there is no reason to anticipate different results because the mechanisms of binding site regulation in the setting of disease or medications are generally not species specific.
The results of the present study, which should be treated as suggestive rather than definitive given the small sample sizes, provide evidence of reduced density of monoaminergic terminals in some sOPCA patients, and give encouraging information concerning the utility of DTBZ in detecting striatal disease by measuring the density of monoaminergic presynaptic terminals. Utilizing only 4 patients with MSA and 8 with sOPCA compared with 9 normal control subjects, the study demonstrated significantly reduced DV in the caudate nucleus of both groups and in the putamen of the MSA group. Ligand $K_{1}$ did not differ between groups, suggesting that the differences in specific binding in the striatum likely do not result from the effects of tissue atrophy. The reductions of DTBZ DV in the striatum were greater in the MSA than the sOPCA group. The sOPCA group had a wide range of specific binding in the striatum, suggesting varying degrees of striatal dysfunction within this group. In contrast, all 4 MSA patients had deficits of striatal DTBZ specific binding, and all had correspondingly severe disturbances of extrapyramidal function associated with autonomic failure. The weaker evidence of decreased DTBZ specific binding in the sOPCA group suggests that at least some of the SOPCA patients had decreased nigrostriatal dopaminergic presynaptic terminals, which is in keeping with the clinical findings of trace levels of rigidity in Patients 7, 9, 11, and 12 and minimally detectable evidence of hypokinetic speech in Patients 5, 6, 7, 9, 10, and 12. Perhaps the sOPCA patients with reduced $D T B Z$ specific binding will proceed over time to develop extrapyramidal symptoms as well as the autonomic symptoms and signs characteristic of MSA.

Even though the MSA patients on average had greater reductions of striatal DTBZ specific binding than did the sOPCA patients, several of the latter had decreased levels, some of which were reduced to the range observed in the MSA patients. As mentioned earlier, in a previous study $[49],\left[{ }^{18} \mathrm{~F}\right]$ fluorodopa was used to investigate dopaminergic presynaptic terminals in parients with the "olivopontocerebellar atrophy form of multiple system atrophy" who probably are similar to the patients with sOPCA in the present study. Review of the data in that study reveals that most of the patients who had decreased $\left[{ }^{18} \mathrm{~F}\right]$ fluorodopa binding showed no signs of extrapyramidal disorder on clinical examination. The results in that study may have been affected by compensatory upregulation of dopa decarboxylase activity and thus may have underestimated the decrease of nigrostriatal terminals in sOPCA. For a ligand to be helpful, it should be sensitive to differentiating disease from normal, which requires a favorable signal-to-noise ratio, and it should be accurate in estimating the severity of disease, which requires absence of bias. Upregulation decreases the "signal" (i.e., the 
difference between the disease state and normal) and probably decreases the sensitivity of the fluorodopa method for detecting loss of nigrostriatal terminals. Moreover, upregulation introduces bias, leading to inaccurate results.

In the present study, the finding of similar levels of decline of DTBZ DV in some of the patients with sOPCA as compared with the MSA group raises the issue of why at least a few of these sOPCA patients did not show clinical signs of extrapyramidal dysfunction. One possible explanation is that the changes in sOPCA were greater in the caudate nucleus than the putamen, whereas it seems likely that abnormal function of the putamen is more strongly related to clinical signs of extrapyramidal dysfunction. Another possibility is that other sites of neural degeneration in the extrapyramidal motor system could mask the clinical expression of extrapyramidal disorder. These may include striatal neurons, but could also involve neurons in the subthalamus and globus pallidus.

All sOPCA patients in this study had clinical evidence of cerebellar dysfunction without symptoms or signs of extrapyramidal disease and without autonomic disorders. The consistent involvement of the cerebellum in these patients accounts for the significant decrease of $K_{1}$ in the sOPCA group as compared with both the MSA and normal control groups. Only 2 of the 4 MSA patients showed clinical signs of cerebellar dysfunction, indicating that these patients probably had degenerative changes in the cerebellum. The other 2 MSA patients probably had mild or no degenerative changes in the cerebellum, and this may explain the lack of significant $K_{1}$ effects observed in the cerebellum of the MSA patients as a group.

These investigations were suppported by grant DE-FGO287ER60561 from the US Department of Energy and grants NS 15655, AG 08671, and AA 07378 from the National Institutes of Health.

\section{References}

1. Quinn N. Multiple system atrophy-the nature of the beast. J Neurol Neurosurg Psychiatry 1989;52(special suppl):78-89

2. Quinn N. Multiple system atrophy. In: Marsden CD. Fahn S, eds. Movement disorders 3. London: Butterworths, 1994:262281

3. Polinsky RJ. Multiple system arrophy. Clinical aspects, pathophysiology and treatment. Neurol Clin 1984;2:487-498

4. Wenning GK, Ben Shlomo Y, Magalhães M, et al. Clinical features and natural history of multiple system atrophy. An analysis of 100 cases. Brain 1994;117:835-845

5. Colosimo C, Albanese A, Hughes AJ, et al. Some specific clinical features differentiate multiple system atrophy (striatonigral variety) from Parkinson's disease. Arch Neurol 1995;52:294-298

6. Wenning GK, Ben Shlomo Y, Maglahāes M, et al. Clinicopathological study of 35 cases of multiple system atrophy. $J$ Neurol Neurosurg Psychiatry 1995;58:160-166

7. Oppenheimer DR, Esiri MM. Diseases of the basal ganglia, cerebellum and motor neurons. In: Hume Adams J, Duchen LW, eds. Greenfield's neuropathology. 5th ed. London: Edward Arnold, 1992:988-1045

8. Kume A, Takahashi A, Hashizume Y, Asai J. A histometrical and comparative study on Purkinje cell loss and olivary nucleus cell loss in multiple system atrophy. J Neurol Sci 1991;101: 178-186

9. Fearnley JM, Lees AJ. Striatonigtal degeneration. A clinicopathological study. Brain 1990;113:1823-1842

10. Gibb WRG. Accuracy in the clinical diagnosis of parkinsonian syndromes. Postgraduate Med J 1988;64:345-351

11. Borit $A$, Rubinstein LJ, Urich $H$. The striatonigral degenerations: putaminal pigments and nosology. Brain 1975;98:101112

12. Takei Y, Mirra SS. Striatonigral degeneration: a form of multiple system atrophy with clinical parkinsonism. In: Zimmerman HM, ed. Progress in neuropathology. New York: Grune \& Stratton, 1973:217-251

13. Cohen J, Low P, Fealey R, et al. Somatic and autonomic function in progressive autonomic failure and multiple system atrophy. Ann Neurol 1987;22:692-699

14. Spokes EGS, Bannister R, Oppenheimer DR. Multiple system atrophy with autonomic failure. J Neurol Sci 1979;43:59-82

15. Sung JH, Mastri AR, Segal E. Pathology of Shy-Drager syndrome. J Neuropathol Exp Neurol 1979;38:353-368

16. Bannister R, Oppenheimer DR. Degenerative diseases of the nervous system associated with autonomic failure. Brain 1972; 95:457-474

17. Papp MI, Khan JE, Lantos PL. Glial cytoplasmic inclusions in the CNS of patients with multiple system atrophy (striatonigral degeneration, olivopontocerebellar atrophy and Shy-Drager syndrome). J Neurol Sci 1989;94:79-100

18. Nakazato $Y$, Yamazaki H, Hirato J, et al. Oligodendroglial microtubular tangles in olivopontocerebellar atrophy. J Neuropathol Exp Neurol 1990;49:521-530

19. Kato S, Nakamura H, Hirano A, et al. Argyrophilic ubiquinated cyroplasmic inclusions in Leu-7-positive glial cells in olivopontocerebellar atrophy (multiple system atrophy). Acta Neuropathol (Berl) 1991;82:488-493

20. Mochizuki A, Mizusawa $\mathrm{H}$, Ohkoshi N, et al. Argentophilic intracytoplasmic inclusions in multiple system atrophy. J Neurol 1992;239:311-316

21. Papp MI, Lantos PL. The distribution of oligodendroglial inclusions in multiple system atrophy and its relevance to clinical symptomatology. Brain 1994;117:235-243

22. Kato $\mathrm{S}$, Nakamura $\mathrm{H}$. Cytoplasmic argyrophilic inclusions in neurons of pontine nuclei in patients with olivopontocerebellar atrophy: immunohistochemical and ultrastructural studies. Acta Neuropathol (Berl) 1990;79:584-594

23. Papp MI, Lantos PL. Accumulation of tubular structures in oligodendroglial and neuronal cells as the basic alteration in multiple system atrophy. J Neurol Sci 1992;107:172-182

24. Lantos PL, Papp MI. Cellular pathology of multiple system atrophy: a review. J Neurol Neurosurg Psychiatry 1994;57: 129-133

25. Eadie MJ. Olivo-ponto-cerebellar atrophy (Dejerine-Thomas type). In: PJ Vinken, GW Bruyn, eds. Handbook of clinical neurology. Amsterdam: North-Holland, 1975:415-431

26. Eadie M]. Olivo-ponto-cerebellar atrophy (Menzel type). In: PJ Vinken, GW Bruyn, eds. Handbook of clinical neurology. Amsterdam: North-Holland, 1975:433-449

27. Berciano J. Olivopontocerebellar atrophy. A review of 117 cases. J Neurol Sci 1982;53:253-272

28. Duvoisin RC. An apology and an introduction to the olivopontocerebellar atrophies. In: Duvoisin RC, Plaitakis A, eds. The olivopontocerebellar atrophies. New York: Raven, 1984 $5-12$ 
29. Harding A. 'Idiopathic' late onset cerebellar ataxia. In: Harding $A$, ed. The hereditary ataxias. Boston: Butterworths, 1984: 166-173

30. Koeppen AH, Baron KD. The neuropathology of olivopontocerebellar atrophy. In: Duvoisin RC, Plaitakis A, eds. The olivopontocerebellar atrophies. New York: Raven, 1984:13-38

31. Koeppen AH. The Purkinje cell and its afferents in human hereditary ataxia. I Neuroparhol Exp Neurol 1991;50:505--514

32. Ferrer I, Genís D, Dávalos A, et al. The Purkinje cell in oljvopontocerebellar atrophy. A Golgi and immunocytochemical study. Neuropathol Appl Neurobiol 1994;20:38-46

33. Kilbourn MR, Lee LC, Vander Borght TM, et al. Binding of $\alpha$-dihydrotetrabenazine to the vesicular monoamine transporter is stereospecific. Eur J Pharmacol 1995;278:249-252

34. Kilbourn MR, Frey KA, Koeppe RA, et al. In vivo imaging of monoaminergic nerve terminal losses using ligands for the synaptic vesicle monoamine transporter. Q J Nucl Med 1995;39: $32-34$

35. Frey KA, Koeppe RA, Kilbourn MR, et al. Presynaptic monoaminergic vesicles in Parkinson's disease and normal aging. Ann Neurol 1996;40:873-884

36. Gilman S, Frey KA, Koeppe RA, et al. Decreased striatal monoaminergic presynaptic terminals in OPCA and MSA demonstrated with ["C]dihydrotetrabenazine and PET. I Cereb Blood Flow Metab 1995; 15 (suppl 1):\$752

37. McLeod JG, Tuck RR. Disorders of the autonomic nervous system: part 2. Investigation and treatment. Ann Neurol 1987; $21: 519-529$

38. Gilman S, Markel DS, Koeppe RA, et al. Cerebellar and brainstem hypometabolism in olivopontocerebellar atrophy detected with positron emission tomography. Ann Neurol 1988;24: $223-230$

39. Kluin KJ, Gilman S, Markel DS, et al. Speech disorders in olivopontocerebellar atrophy correlate with positron emission tomography findings. Ann Neurol 1988;23:547-554

40. Koeppe RA, Frey KA, Vander Borght TM, et al. Kinetic evaluation of [C-11]dihydrotetrabenazine (DTBZ) by dynamic PET: a marker for the vesicular monoamine transporter. J Cereb Blood Flow Metab 1995;15:S651
41. De Volder AG, Francart J, Laterre C, et al. Decreased glucose utilization in the striatum and frontal lobe in probable striatonigral degeneration. Ann Neurol 1989;26:239-247

42. Eidelberg D, Takikawa S, Moeller JR, et al. Striatal hypometabolism distinguishes striatonigral degeneration from Parkinson's disease. Ann Neurol 1993;33:518-527

43. Gilman S, Koeppe RA, Junck L, et al. Patterns of cerebral glucose metabolism detected with PET differ in multiple system atrophy and olivopontocerebellar atrophy. Ann Neurol 1994;36:166-175

44. Fulham MJ, Dubinsky RM, Polinsky RJ, et al. Computed tomography, magnetic resonance imaging and positron emission tomography with $\left[{ }^{18} \mathrm{~F}\right]$ fluorodeoxyglucose in multiple system atrophy and pure autonomic failure. Clin Autonom Res 1991; $1: 27-36$

45. Perani D, Bressi S, Testa D, et al. Clinical/metabolic correlations in multiple system atrophy. Arch Neurol 1995;52:179185

46. Bhatt MH, Snow BJ, Martin WRW, et al. Positron emission tomography in Shy-Drager syndrome. Ann Neurol 1990;28: $101-103$

47. Brooks DJ, Salmon EP, Mathias CJ, et al. The relationship between locomotor disability, autonomic dysfunction, and the integrity of the striatal dopaminergic system in patients with multiple system atrophy, pure autonomic failure, and Parkinson's disease, studied with PET. Brain 1990;113:15391552

48. Burn DJ, Sawle GV, Brooks DJ. Differential diagnosis of Parkinson's disease, multiple system atrophy, and SteeleRichardson-Olszewski syndrome: discriminant analysis of striatal ${ }^{18}$ F-dopa PET data. J Neurol Neurosurg Psychiatry 1994; $57: 278-284$

49. Rinne JO, Burn DJ, Mathias CJ, et al. Positron emission tomography studies on the dopaminergic system and striatal opioid binding in the olivopontocerebellar atrophy variant of multiple system atrophy. Ann Neurol 1995;37:568-573

50. Kish SJ, Robitaille Y, El-Awar M, et al. Striatal monoamine neurotransmitters and metabolites in dominantly inherited olivopontocerebellar atrophy. Neurology 1992;42:1573-1577 